Boise State University

ScholarWorks

$1-2020$

\title{
Accessibility Best Practices, Procedures, and Policies in Northwest United States Academic Libraries
}

\author{
Rebeca Peacock \\ Boise State University \\ Amy Vecchione \\ Boise State University
}




\section{Accessibility Best Practices, Procedures, and Policies in Northwest United States Academic Libraries}

\section{Abstract}

Academic libraries are responsible for providing accessible copies of collection materials to individuals facing a variety of accessibility needs. Accessibility needs differ from user to user, often making each request an individualized service. However, do academic libraries have a responsibility to embrace a Universal Design for Learning approach to their acquisitions process? Do academic library workers need to establish policies as part of the procurement process? This research surveyed academic libraries at institutions similar to Affiliated University in size, graduate program offerings, and within the same region to help answer the questions: how academic libraries in the Northwest United States establish practices, policies, procedures, and workflows to meet these needs, and: how do academic libraries currently meet these needs when providing streaming media services, and other collection materials, to users with accessibility needs?

\section{Keywords}

accessibility, higher education, academic libraries, video, multimedia, streaming video, universal design for learning

\section{Introduction}

Instructors in K-12 classrooms have long provided accessible materials due to the indepth tracking of students with disabilities by school officials. However, when these same students enter into higher education the onus is on them to communicate with the institution, including their instructors, and various other offices, about their disability so that accessible materials are provided. Not all students choose to self-identify, potentially jeopardizing their academic performance. Recently, the trend trajectory in higher education is towards using Universal Design to improve educational materials to meet accessibility needs. Universal Design has been shown to improve learning for all students, not just students with specific accessibility needs (Gordon, Meyer, \& Rose, 2016). Academic libraries play a large role in helping faculty find instructional material whether it is a book, article, or video. Therefore, a campus' library is often responsible for providing accessible materials. 
The goal of this research is to gain a preliminary understanding of current practices and glean information about perceptions and procedures regarding accessibility needs; especially as they pertain to the acquisition of multimedia materials in Northwest academic libraries. This article will describe our methods and findings before providing information that can be used to educate library workers on the accessibility needs, best practices, common workflows, and potential procedures to implement to ensure they serve all users regardless of disability.

\section{Literature Review}

\section{Accessibility}

The Rehabilitation Act of 1973 prevents discrimination against those with disabilities in any organization that receives federal funding. This act, coupled with the Americans with Disabilities Act of 1990, provides a solid foundation protecting the rights to those with disabilities. Neither act, however, speaks directly to the use of technology or the internet. Therefore, in 1998 Congress amended the Rehabilitation Act, amending section 508 which deals specifically with electronic and information technology (GSA Government-wide IT Accessibility Program, 2018). The standards in this amendment were later revised based on work done by outside organizations such as the World Wide Web Consortium Web Content Accessibility Guidelines (WCAG 2.1) and the policies described by the European Union for products and services in the European Accessibility Act (European Commission, 2018).

In 2009, the American Libraries Association (ALA) issued recommended guidelines to libraries for the "purchasing, procuring, using, maintaining and contracting for electronic resources" (American Library Association, 2019). This included a recommendation that libraries obtain guarantees from vendors that their products follow Section 508 regulations and other accessibility guidelines. However, the degree to which these recommendations have been adopted by academic libraries is unclear. Furthermore, lawsuits such as at the University of Montana (University of Montana, 2014) have increased the visibility and need to put the ALA recommendations into practice in these libraries. In this case, which took place at a public university in the western United States, an individual filed an Office of Civil Rights (OCR) complaint was filed against the university. This filing requested that the university must provide accessible documents, videos, and specifically, inaccessible library database materials (University of Montana, 2014, p. 1). The remediation recommendations not only included campus training on accessibility but specifically states that the library must review new acquisitions for inaccessibility as well as provide an accessible search engine capable of searching across all library materials (University of Montana, 2014, p. 5). The results of this case impact all public universities and their responsibilities.

\section{Universal Design}

The Universal Design for Learning (UDL) framework, developed in the 1990s, provides a guide for the creation of instructional materials that can be used by every student equally, 
regardless of disclosure of disability (Gordon, Meyer, \& Rose, 2016). In short, all materials provided to students should meet accessibility guidelines set by groups such as the American Foundation for the Blind (AFB), National Association of the Deaf (NAD), and WCAG 2.0. In recent years, UDL has permeated higher education with many institutions adopting these guidelines into faculty training and course design requirements. The Association of Research Libraries also provides a helpful overview for libraries which lists technical standards (Association of Research Libraries, 2014).

At Affiliated University, Policy \#2080 dictates that "Faculty are responsible ensuring that the selection and/or development of their course tools and materials are fully accessible for people with disabilities" (Affiliated, 2017). The following departments have embraced the UDL framework as a method of course development: The Center for Teaching and Learning, Instructional Design and Educational Assessment Shop (IDEA Shop), eCampus (the online course department at Affiliated University), the Educational Access Center, and the Albertsons Library. Affiliated Library specifically supports a UDL framework for faculty use of library purchased electronic content such as PDF articles, book chapters, eBooks, Videos, and Streaming Video Platforms.

\section{Collection Development}

Librarians and library workers in publicly-funded academic and public libraries in the United States have implemented a variety of models of collection development, always with the goal to provide access to information, "A primary responsibility of academic libraries includes supporting users' access to resources and services" (Blummer \& Kenton, 2017). Cost, type of format, and information needs are some of the criteria librarians with collection budgets use to make decisions. In recent years, collection choices have become increasingly about need and cost. In addition, making collections accessible can be costly. This hurdle may be one reason that electronic collections are not always made accessible. Library workers have prioritized services for the blind, such as braille services. However, other types of accessibility needs are not always given a high priority. The National Library Service for the Blind and Physically Handicapped was established by an act of Congress in 1931. Since that time they have been successful in expanding expanded services, formats, and types of information to meet the needs of the users they serve. Services like the Talking Books Service have been efficient in helping those who cannot see well enough to read, and those unable to physically hold a book. However, these services fail to meet the needs of other users with accessibility needs, such as the hearing impaired (National Library Service, 2019). These services can do more work to define how to meet accessibility needs with regard to all formats and all disabilities.

Within the context of higher education, academic libraries provide many collection materials via electronic format and delivery. This often makes it challenging to provide accessible formats for all users. The increase in electronic formats has led to "questions about accessibility for individuals with disabilities. In academic libraries, providing accessible electronic information resources ensures equal access and opportunity to information" (Ostergaard, 2015). Some researchers and libraries encourage library workers to "modify your Collection Development policy to include language valuing accessible electronic resources" (Ostergaard, 
2015). Historically some formats and accessibility needs are prioritized over others, captions and audio description in particular. Because of this, academic library video collections continually struggle to meet the needs of library users who need captions and audio description. In 2012, librarians at New York University published a guide designed to help librarians and library staff to make video content long-lasting analyzing how to make copies and when. Interpreting Section 108 of the Copyright Act, they defaulted to making video more accessible (Besser, et. al., 2012). These guidelines do not make the case for when an item is unviewable to an individual, only when the conditions of the format have deteriorated or are lost. While many libraries are working to digitize their obsolete content, they are also adding captions when and where it is possible to do so. Eberhardt writes that making video content accessible, "is a high priority for educational institutions" (2018).

The law conflicts in terms of how libraries and universities ought to provide materials in a variety of formats to meet user needs. The conflict is between the areas of the law regarding copyright ownership and accessibility, "Current U.S. copyright law lacks a blanket exception for accessibility, relying instead on a patchwork of statutory exceptions and the doctrine of fair use" (Scheid, 2015). However, library staff and librarians still have a responsibility and an obligation to uphold the American Disabilities Act (McCann \& Peacock, 2019), and must collaborate to improve access of video and other formats for all library users (Keenan, 2018).

\section{Methodology}

The author's developed and asked questions regarding accessibility policy on their campus and how they make decisions in their library about content acquisition, specifically multimedia, with accessibility in mind. This survey methodology is supported by the 2019 LYRASIS Accessibility Survey which also includes questions such as: "Question 1: Does your institution have an accessibility policy for digital content acquisition?" and "Question 6: What documentation do you request from content providers to enforce your accessibility policy?". The authors developed thirteen questions, approved by the Institutional Review Board (IRB) at Affiliated University, (see Appendix A) including likert-like scale items, yes/no prompts, and open responses. The authors created the questions after consulting with two primary stakeholder groups including the Affiliated University Accessible Content Community of Practice (COP) and Albertsons Library acquisitions staff. This Community of Practice asked for more information in order to gain a deeper understanding of how libraries make decisions and support they provide for campus accessibility processes. In addition, Albertsons Library acquisitions staff consulted on information they would be interested in knowing about accessibility practices in purchases from other departments in the region. No questions forced a response other than the first question which provided consent for data collection. The authors designed the survey this way initially should participants not know the response to a question or if the question asked for sensitive information the individual felt uncomfortable answering per the IRB protocol approved.

The participant population for this study was identified by selecting library workers who work in academic libraries and who are employed in an acquisitions role within their library. This selection was chosen because these individuals would have a vested interest in the results and 
increase response rate (Saleh \& Bista, 2017). The authors selected similarly-sized public institutions to Affiliated University located in the region of the Northwest and Intermountain West of the United States. Each institution selected is a public, research institution. These institutions were selected based on the number of students and the types of degrees that they confer with the assumption that their practices and constraints would be most similar to Affiliated University. Each region and state has differing laws regarding funding models, even though all universities have the same federal responsibilities. As a result, identifying methods to deliver these services in states that typically underfund library services, such as the Northwest and the Mountain West, helps to build support. The authors believe in many cases regional institutions share more in common with each other than institutions across the country. In identifying the issues of a particular region, these institutions, who likely already have relationships, can share best practices and work together to enact change at a local, state, or regional level.

Due to the fact that our research takes place in city, Idaho, which is a geographically isolated area, the authors selected a methodology for peer selection based on a 2018 article including a method for identifying peers from Idaho State University by Jardine, Shropshire, and Koury (2018). The authors contacted library workers in decision-making positions regarding collections and acquisitions at their libraries. Persons to contact and their contact information was determined by reviewing the organization charts and websites of the selected institutions, ultimately choosing individuals from those with similar graduate-level programs to Affiliated University.

Once the list of peer institutions and contacts were determined, the authors sent a personalized email inviting them to participate in the research study. Perkins (2011) found that a personalized email sent to a stakeholder increases the trust of those you want to participate in the survey increasing response rate. The authors sent a follow-up email to those who agreed to participate, inviting them to participate in a Qualtrics survey on how they make decisions regarding accessibility in their collections. This email provided the required IRB consent information for participation and was sent in October 2018.

\section{Results}

A total of 16 participants were selected representing those institutions in the Northwest with similar characteristics to Affiliated University. Of those contacted, $n=10(62.5 \%)$ completed the survey.

\section{Accessibility Training in Universities and Libraries of Peer Institutions}

To gain a deeper understanding of peer institutions and their knowledge of accessibility, participants were asked about training in accessibility needs for libraries. When asked whether their institution had conducted training related to accessibility needs in libraries, $60 \%$ of participants indicated that training had been offered. However, when asked if the individual 
responding to the survey had taken the training, only $40 \%$ indicated they had participated in the training.

\section{Library Video or Streaming Media Purchasing Decisions Based on Accessibility}

Participants were asked to use a Likert scale to indicate the degree to which their institution purchases video or streaming media based on accessibility needs. In Figure $180 \%$ of the participants indicated that accessibility is used in purchasing decisions "Some of the time". In addition, one participant indicated that their institution uses accessibility all of the time. Therefore, in total, $90 \%$ of participants indicated that they used accessibility to some degree in the decision-making process, while one participant indicated that their institution almost never uses accessibility in the decision-making process for these materials.

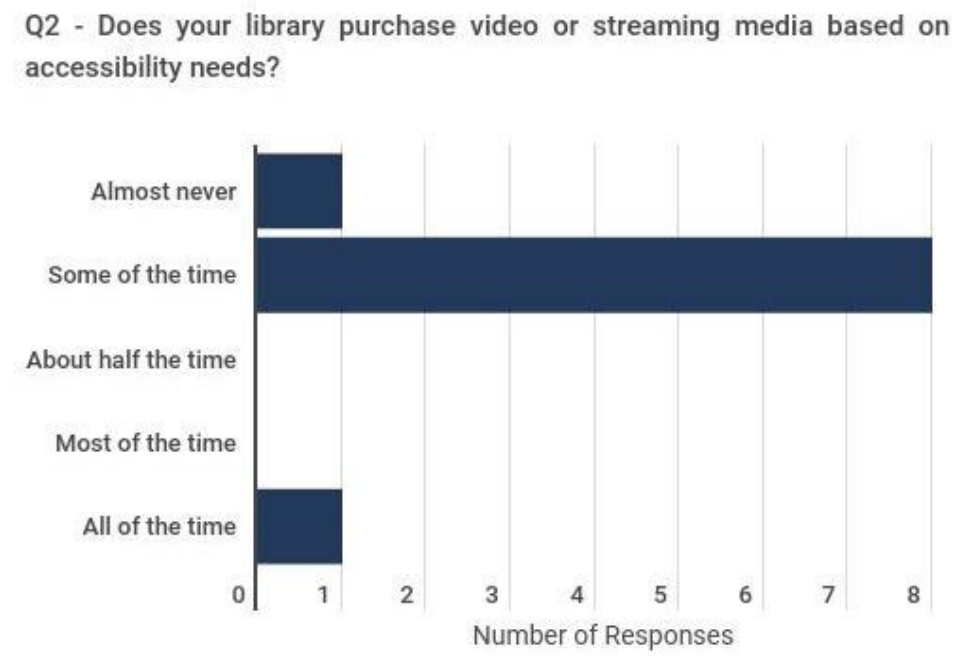

Figure 1 Responses to Survey Question 2: The figure shows the responses to a survey question regarding purchasing decisions of video or streaming media based on accessibility.

\section{Campus Responsibility for Providing Accessible Course Materials}

Participants were asked to use a Likert scale to indicate levels of responsibility for various entities on a university campus including: course instructors, administrators, library support staff, department support staff, vendors, and student accessibility support centers. The results are shown in Figure 3. Overall, participants perceived that their institutions place the heaviest responsibility on a student accessibility support center. One participant also indicated that both course instructors and vendors share the heaviest responsibility. In addition to this, $40 \%$ of participants believe that their institutions place some responsibility on course instructors, library support staff, and vendors. Also, $60 \%$ of participants were either unsure of their responsibility or felt that their institutions placed little responsibility on department support staff 
and administrators. It is important to note that this question yielded an inconsistent response rate. For each category, at least three respondents choose not to answer the question.

\section{Q7 - Based on your knowledge of your institution, who is responsible for making course material accessible?}

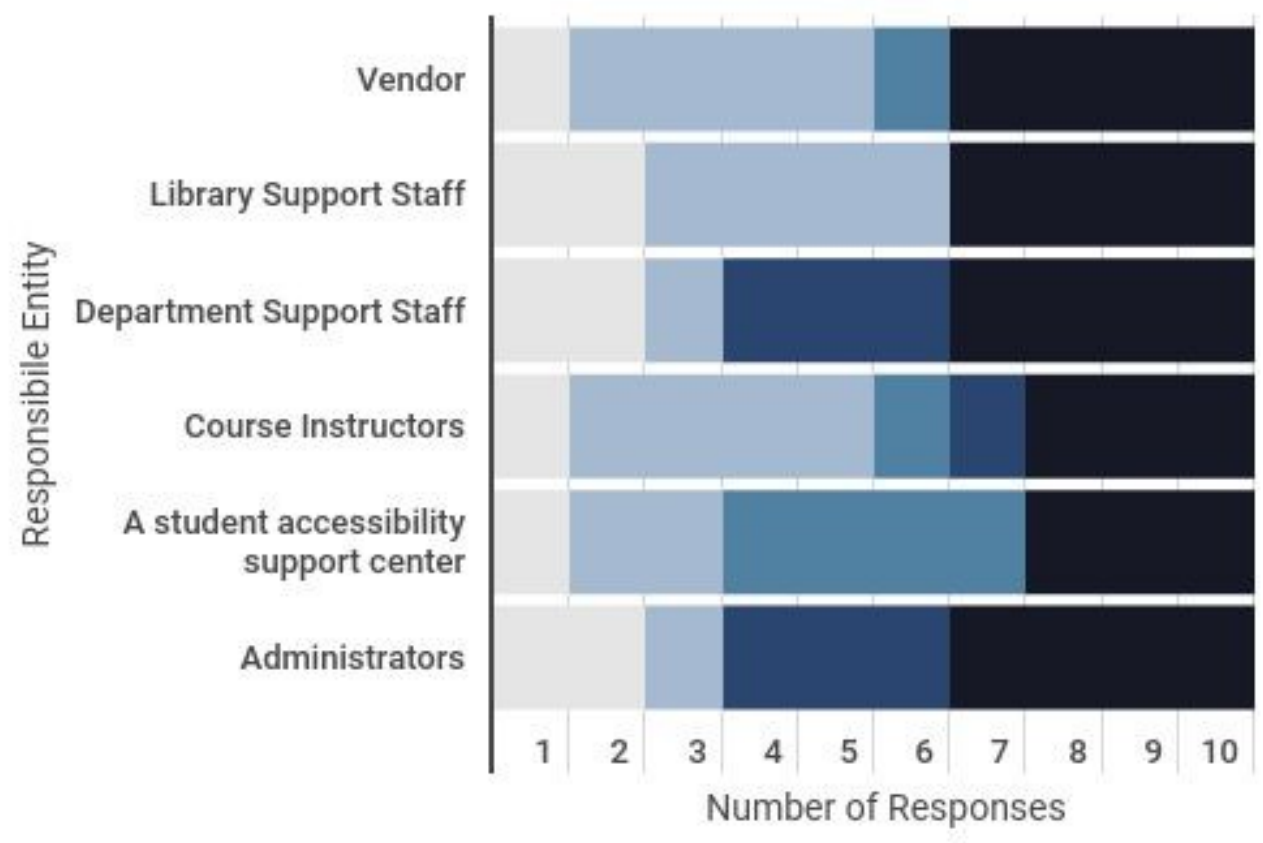

No Responsibility

Some Responsibility

Heavy Responsibility

I am unware

No Response

Figure 2 Responses to Survey Question 7: This figure presentations the array of responses to a survey question regarding who on university campuses is responsible for meeting accessibility needs.

\section{Institutional and Library Purchasing Policies for Accessible Technology}

Participants were also asked to provide information on their campus and library purchasing policies. When asked whether their institution had a policy or guideline document for purchasing accessible materials; $80 \%$ of respondents indicated they did not. The other $20 \%$ of participants indicated that their institution does have one of these documents in place but did not provide further details. When asked if their institution's library agreements with vendors are written so that media content acquisitions are always accessible, all of the participants (100\%) responded they did not. Additionally, when asked whether their institutions secure permissions 
to caption licensed materials in their vendor agreements only $30 \%$ indicated that these permissions are include.

\section{Potential Barriers to Providing Accessible Video or Streaming Media}

In order to establish a baseline understanding of the kinds of support institutions offer academic libraries to meet accessibility needs, participants were asked about budgets to purchase captions and other resources available to library staff such as training, hardware, or software. In general, it seems institutions are not currently offering much to help library staff meet the accessibility needs of users including supporting budgets. The resources are scattered, and not uniform based on the responses from library staff. One clear consistency is that, in terms of budget, $70 \%$ of participants indicated that their library has no budget nor funding available to purchase captions at their institution.

\section{Discussion}

The rate of completion of this survey utilized in this study provides an overview of various Northwest institutions for evaluating trends in acquisitions practices in relation to accessibility. The response to these survey questions suggests that the practice of including UDL in acquisitions is still being explored by some academic libraries in the Northwest. While the responding institutions are considering these practices and putting measures in place they have not yet been fully adopted as a practice by academic libraries.

\section{Knowledge and Training}

The primary finding from the results from this study is that the librarians and library staff who completed the survey identified gaps in their institution's support for accessibility needs of users and legal responsibilities of libraries to meet those needs. Additionally, the libraries and universities considered often lacked a comprehensive policy to facilitate library services being able to meet those needs. In addition, $60 \%$ of respondents indicated that their library has offered training, only $40 \%$ of respondents have participated in this training. This finding is supported by the national LYRASIS Accessibility Survey (2019) which found that most respondents learned about accessibility through either self-study or webinars. The rules surrounding accessibility are quite complex and learning from experts can help an institution avoid costly mistakes.

While institutions are responsible for providing accessible materials, it's clear (Figure 2) that not all librarians and library staff are aware of who specifically is responsible for carrying out this work. A comment from one of the respondents was that substantial committee work had 
taken place on campus, but that when the leader of that group departed their position, so did the initiative for accessible practices. The ability to identify other departments or individuals on campus with whom to collaborate with on resources and policies benefits the entire institutions role in supporting student needs. Knowing who at an institution to collaborate with on resources and policy can help an institution's role in supporting student needs.

Library staff are trying to use accessibility needs in their decision-making process, but express some confusion regarding how to proceed. For example, one participant answered, "I would have liked to say 'I don't know' to many of these questions but was only given the option of Yes or No." This limitation provides insight for future survey development but also provides an important insight into the state of academic libraries. Library staff and librarians are at a place where they are still considering user accessibility needs in their purchasing.

\section{Institutional Strategy}

While libraries do appear to recognize the need to purchase accessible materials, they may be unable to fully implement a consistent strategy. The majority of the respondents surveyed indicated that their institution only purchases accessible materials "some of the time," suggesting that there are some barriers to implementing these policies. These data do not allow definitive conclusions to be drawn on the reason or reasons for this. However, one significant barrier identified is a lack of support through budgets for accessible materials. It is notable that one institution did indicate that they always purchase accessible materials. Further research could help illuminate the strategies and campus policies that may have helped this institution achieve that benchmark. Knowledge and training in accessibility was also low. This could be another reason that a library may, at this time, not know enough about accessibility issues to create comprehensive internal policy or successfully advocate for funding to make accessibility a priority.

It was also found that many respondents seemed unclear as to whom on their campuses are ultimately responsible for making course material accessible. This can lead to a confusing campus workflow where library workers, faculty, and other support staff are unsure where to seek advice on best practices and how to get help for their students. This also leads to inconsistencies in accessibility implementation. Accessibility is a crucial campus conversation that all faculty and staff should be a part of so that they know exactly what to do and who to turn to for support. Compared to the rest of the survey, relatively few respondents answered the question of whose responsibility it is to make materials accessible (see Figure 2). We are unsure if this question was intentionally skipped or whether instead of using the "I am unaware" option, the respondents chose to leave the question blank. However, one clear conclusion from this question was that a campus accessibility support center was found to be the entity that was seen as having the most responsibility for creating accessible materials. In this context, the authors note that the accessibility support center at our home institution has indicated that they will only remediate materials for students who self-identify, due to budget constraints. This leaves out a potentially large population of students who may need accessible materials but refuse to self-identify. If student support centers face similar constraints at other institutions it is possible that faculty and staff may be required to take on more of this responsibility. We note 
that most respondents indicated that on their campus faculty and library staff currently held some responsibility.

Finally, it is crucial for our profession moving forward that most respondents thought that vendors have some level of responsibility in making materials accessible. In our experience vendors have varying levels of accessibility support. Some vendors have made most of their materials accessible, while other vendors put materials in a queue and make them accessible when a customer submits a request. However, some vendors still indicate that accessibility is not a priority or possibly haven't made their materials accessible due to licensing and copyright concerns in their vendor contracts. It is clear that library workers believe that vendors share some of the responsibility, although, libraries are not currently enforcing this through procurement policies. Interestingly, no responders felt that library support staff have a heavy responsibility, despite libraries bearing the financial burden of a product some students may not be able to use.

\section{Policy}

Ultimately, it seems that in most cases both university and library policy does not currently support consistent advocacy or purchasing of accessible materials. A minority of respondents did indicate that their institution does have a policy/mandate/procedure/practice/recommendation for purchasing accessible materials. However, none of the respondents shared the policies in the survey. We are unsure as to why this information was not shared with us and so we are unable to draw conclusions from this question. It is possible respondents know the information exists but not where it might exist. This is itself a concern as it draws focus to a potentially greater issue that higher education has not fully considered the implications of accessibility and therefore policy is not readily available or shared with all constituents. Finally, most of the respondents indicated their library does not have a universal vendor agreement for purchasing accessible materials. Additionally, the majority of respondents also do not have a clause within their vendor agreements that allows for institutional captioning of materials. It, therefore, seems appropriate to conclude that the library profession still has some work to do to raise awareness on these issues and support the guidelines set forth by the ALA (American Library Association, 2019).

\section{Library Model of Adopting Accessible Practices in Acquisitions}

After reviewing the Northwest data in this study, the authors have identified patterns in how institutions have adopted a UDL framework. From these patterns, the authors have created the "Library Model of Adopting Accessible Practices in Acquisitions" as way for libraries to identify their organization along a pathway, and look forward to continually improve their expertise, services, and adoption of UDL. Though "Adopting" is the final column on this list, once a library has achieved this status, they must be responsible to the user groups by continually iterating these services based on the needs of users. 
To use the model below, library staff are encouraged to read through the actions under each title of the model beginning with "Initiating" on the left. If the majority of the actions in this column apply to your organization, then this is where you will begin to develop a plan for your institution to develop further. Use the next column in succession to help plan a roadmap until you have reached Adopting. At this point you will want to develop a continual process of policy review, evaluating collaborations beyond your institution, and receiving training on an ongoing basis to ensure current practices are mirrored by the institution.

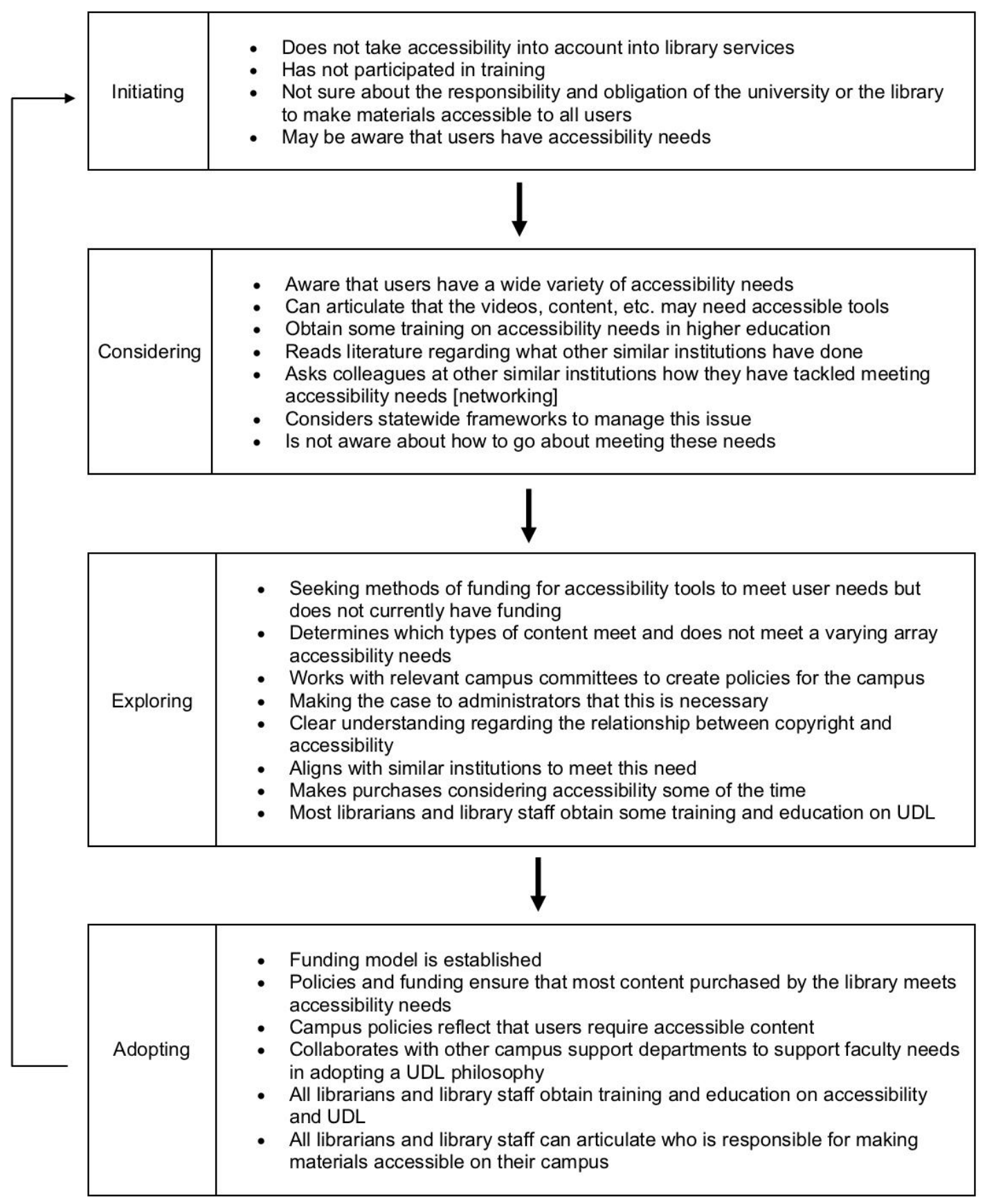


Figure 3. Library Model for Adopting Accessible Practices in Acquisitions: This model provides a framework for moving toward full adoption on UDL in an academic library

\section{Conclusion}

Academic libraries in the Northwest United States are not adequately planning to meet accessibility needs for users of library collections on college campuses. This study shows that the need to provide video captioning for users on multimedia content acquisitions is a trend in academic libraries. Some of the individuals consulted had not yet considered, or have only begun to consider these issues, and left several questions unanswered. Due to the fact that this study's goal was to gather a preliminary overview, the authors cannot yet draw firm conclusions on the reasons why this is the case. However, based on the information gathered thus far, we suspect it is due to a combination of available funding, library staff and librarian training and education needs, a lack of clear policy, and also conflicting priorities, especially in regard to copyright vs. accessibility. Our survey identified that these factors were somewhat lacking across most of the institutions in our sample.

Further research will be necessary to provide a more detailed overview of the status of accessibility in library purchasing on a regional basis in the rest of the United States, as well as at a national level. In addition, state organizations will also need to establish workflows and funding mechanisms for how to fund this required service with public universities. The findings of this study show that there is a need for more education, training, and administrative support to provide accessible content to library users. While it is partially a library's responsibility on our campuses to provide accessible library materials, it is also the responsibility of our vendors to provide this service especially when the media is hosted on their platforms which are supposed to be accessible for the public. This education may help libraries advocate for their campuses and craft well information contracts for future purchases, ensuring vendors abide by federal laws that govern public education in this country. These conclusions are supported by the national 2019 LYRASIS Accessibility Survey and we echo the call for "more definitive policies" and that "support for training needs organizational commitment" (p. 40). Libraries ought to connect with regional and statewide peers in order to address policy and workflow considerations at the local level. By assessing these needs, and collectively describing the issues at hand, librarians can improve access for individuals with access needs. In creating an advocacy plan library leaders can argue for more resources to meet these needs. This type of advocacy will also encourage local universities to make similar, incremental, and right sized changes.

In addition, as noted in this study, some libraries have been able to make a transition to making accessibility in multimedia content acquisitions a priority. While we were unable to determine the root causes of this, we believe that this study opens up dialog between libraries as to why we have not been able to bridge this gap in our services. We ask the question: are publishers responsible, or academic libraries (University of Montana, 2014)? As our campus begins the process of discussing how departments that support teaching and learning can ensure a Universal Design for Learning philosophy on campus we hope that we can engage others in a discussion and through partnerships on a local, regional, and national level, we can shift vendor priorities, ensuring that academic libraries do not carry the sole burden but rather share it with those we are paying for content. 


\section{Acknowledgement}

We would like to thank the libraries that participated in this survey. Their feedback and candor provided essential information that will help our region and nation work towards a UDL focus in library purchasing. In addition, a special thank you to Affiliated University Affiliated Library's acquisitions department and the Accessible Content Community of Practice for helping identify survey questions.

\section{References}

American Library Association. (2019). Library Service to Persons with Disabilities: Web Accessibility Guidelines. Retrieved May 30, 2019 from http://libguides.ala.org/libservicedisability/web-accessibility

Association of Research Libraries. (2014). Web Accessibility Toolkit: Making digital resources usable \& accessible in research. Retrieved August 19, 2019 from https://accessibility.arl.org/

Besser, H., Brown, M., Clarida, R., Forsberg, W., Righter, M., \& Stoller, M. (2012). Video At Risk: Strategies for Preserving Commercial Video Collections in Libraries. Retrieved August 19, 2019 from https://guides.nyu.edu/ld.php?content id=24818036

Blummer \& Kenton Alphin, H., Jr., Lavine, J., \& Chan, R. (Eds.). (2017). Disability and equity in higher education accessibility (Advances in educational marketing, administration, and leadership (AEMALI) book series). Hershey, PA: IGI Global, Information Science Reference.

Boise State University. (2017). Policy Title: Equal Access for Students with Disabilities. Retrieved August 19, 2019 from https://policy.boisestate.edu/student-affairs/equal-access-forstudents-with-disabilities/

Eberhardt, G. (2018). Making Video Content Accessible. America Libraries Magazine Blog. Retrieved August 19, 2019 from https://americanlibrariesmagazine.org/blogs/the-scoop/makingvideo-content-accessible/

European Commision. (2018). European accessibility act. Retrieved September 5, 2019 from https://ec.europa.eu/social/main.jsp?catld=1202\#navltem-1

GSA Government-wide IT Accessibility Program. (2018). IT Accessibility Laws and Policies. Section508.gov Retrieved from https://www.section508.gov/manage/laws-and-policies

Gordon, D., Meyer, A., \& Rose, D. (2016). Universal design for learning. Peabody: CAST Professional Publishing. Retrieved August 19, 2019 from http://udltheorypractice.cast.org/login 
Jardine, S., Shropshire, S., \& Koury, R. (2018). Credit-Bearing Information Literacy Courses in Academic Libraries: Comparing Peers. College and Research Libraries, 79(6), 768.

doi:https://doi.org/10.5860/crl.79.6.768

Keenan, T. (2018). Collaborating to improve access of video for all. Reference Services Review, 46(3), 414-424. Retrieved May 30, 2019 from https://doi.org/10.1108/RSR-03-2018-0028

McCann, S, \& Peacock, R. (2019). Be an ally for accessibility: Tips for all librarians. College \& Research Libraries News. College \& Research Libraries News, 80(5), 266.

doi:https://doi.org/10.5860/crln.80.5.266

National Library Service. (2019). Overview - The National Library Service for the Blind and Physically Handicapped. Retrieved August 19, 2019 from https://www.loc.gov/nls/about/overview/

Ostergaard, K. (2015). Accessibility from Scratch: One Library's Journey to Prioritize the Accessibility of Electronic Information Resources. The Serials Librarian, 69(2), 155-168. doi: https://doi.org/10.1080/0361526X.2015.1069777

Perkins, R. (2011). Using Research-Based Practices to Increase Response Rates of WebBased Surveys. Educause Review. Retrieved August 23, 2019 from https://er.educause.edu/articles/2011/6/using-researchbased-practices-to-increase-responserates-of-webbased-surveys

Rosen, H. \& Grogg, J. (2019). LYRASIS 2019 Accessibility Survey Report. LYRASIS, 1-42. Retrieved September 13, 2019 from www.lyrasis.org/technology/Pages/Accessibility-Survey$\underline{\text { Report.aspx }}$

Scheid, S. (2015). Copyright and Accessibility. Ohio State University. Retrieved August 19, 2019 from https://library.osu.edu/site/copyright/2015/08/28/copyright-and-accessibility/

Saleh, A. \& Bista, K. (2017). Examining Factors Impacting Online Survey Response Rates in Educational Research: Perceptions of Graduate Students. Journal of MultiDisciplinary Evaluation, 13(29), 63-74. Retrieved August 23, 2019 from http://journals.sfu.ca/imde/index.php/jmde 1/article/download/487/439/

University of Montana. (2014). Resolution Agreement. Retrieved August 30, 2019 from http://www.umt.edu/accessibility/docs/AgreementResolution March 7 2014.pdf 


\section{Appendix A}

Accessibility Policies, Procedures, and Best Practices in Academic Libraries in the Northwest United States

1. Does your library purchase video or streaming media based on accessibility needs? Almost never

Some of the time

About half the time

Most of the time

All of the time

1a. Has your university/college conducted training on accessibility needs in libraries?

Yes

No

1b. Have you completed training on accessibility needs in libraries?

Yes

No

1c. [if no] Is accessibility for library materials a conversation that is taking place at your institution?

Yes

No

2. Does your university/college have a campus accessibility purchase practice?

Yes

No

2a. [If yes] Based on your knowledge of your institution, who is responsible for making course material accessible?

Course instructors [I am unaware, no responsibility, some responsibility, heavy responsibility]

Administration [I am unaware, no responsibility, some responsibility, heavy responsibility] 
Library support staff [I am unaware, no responsibility, some responsibility, heavy responsibility]

Department support staff [I am unaware, no responsibility, some responsibility, heavy responsibility]

Vendor [I am unaware, no responsibility, some responsibility, heavy responsibility]

A student accessibility support center [I am unaware, no responsibility, some responsibility, heavy responsibility]

3. Does your university/college have a policy/mandate/procedure/practice/recommendation that specifically states that purchases will not be made if they are not accessible?

Yes

No

3a. [if yes] What does it stipulate? Fill in question

4. Are your library's agreements with publishers written so that media purchases made are always accessible?

Yes

No

4a. [if no] Does your library have to proactively make a request to the vendor for captions? Fill in question

5. Do your agreements with vendors include permission to caption licensed material? Yes

No

6. Does your library have a budget to purchase captions for media, such as from a company like 3PlayMedia, if the vendor does not have them?

Yes

No

6a. [if no] Who on campus would caption material? Fill in question

7. How many hours a week do your library's staff review potential purchases regarding accessibility?

Fill in question

8. What resources does your university/college offer to supply captions for library materials? (select all that apply)

Software

Hardware, such as computers

Transcribers

Funding to purchase captions

Contracts with vendors 
Training to become proficient in captioning Recognition for providing accessible materials Other (please explain):

9. Based on your knowledge of your university/college, is there a fair use policy/mandate/procedure/practice/recommendation that the campus uses to make media content available when ADA [link] compliance and Copyright [link] are at odds? Please see the following example from UC's system presidential policy https://policy.ucop.edu/doc/2100007/FairUse

"To fulfill its teaching, research, and public service mission, it is the policy of the University of California to encourage the broad dissemination and use of information in accordance with copyright law. The University will defend its employees who use copyrighted materials in an informed, reasonable, and good faith manner, and within the scope of their University employment."

Yes

No

10. Please use the following space to provide additional information on any aspect of accessibility you believe would be useful to the investigators.

Fill in question 